\title{
Como a filosofia pode iluminar a gestão pública em tempos de polarização política
}

\author{
ELLYSSON FERNANDES ROSA ${ }^{1}$ \\ ESTELA NAJBERG ${ }^{2}$ \\ LAUREN DE LACERDA NUNES ${ }^{3}$ \\ JOÃO LUIZ PASSADOR ${ }^{4}$
}

\begin{abstract}
${ }^{1}$ FACULDADE UNIDA DE CAMPINAS (FACUNICAMPS), GoIÂNIA - GO, BRASIL

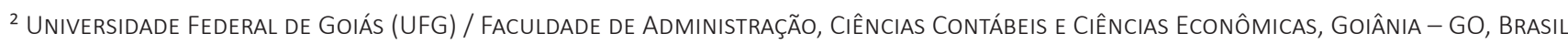

${ }^{3}$ UNIVERSIDADE FEDERAL DO PAMPA (UNIPAMPA), SÃO BORJA - RS, BRASIL

${ }^{4}$ Universidade de SÃo PaUlo (USP) / Faculdade de EConomia, Administração e Contabilidade de Ribeirão Preto, Ribeirão Preto - SP, Brasil
\end{abstract}

\begin{abstract}
Resumo
A polarização tem dominado o cenário político global na última década e afetado a governança pública. O objetivo deste estudo é demonstrar que, por meio da compreensão do pano de fundo filosófico, da política e de técnicas gerenciais, o gestor da coisa pública poderá analisar, de forma mais clara, as oportunidades que envolvem a tomada de decisão nos ambientes governamentais, evitando a polarização nociva de ideias hodiernamente presente no ambiente público. Por meio deste ensaio teórico, espera-se contribuir para o conhecimento das naturezas que compõem a estrutura do conhecimento aplicado à administração pública, bem como para a separação entre o institucional e o privado. Com isso é possível evitar a reificação das opiniões políticas e manter o espírito democrático, o que permitiria ao gestor tornar-se mais propício, sem abster-se de suas conviç̧ões, a considerar a pluralidade de ideias e tender a ser mais tolerante com as opiniões contrárias, sem perder o foco na melhoria da qualidade de vida da sociedade como corolário imparcial e científico da gestão pública.
\end{abstract}

Palavras-chave: Administração pública. Gestão pública. Ética. Filosofia. Polarização política.

\section{How philosophy can enlighten public management in times of political polarization}

\begin{abstract}
Polarization has dominated the global political outlook for the past decade and has affected public governance. This study aims to demonstrate that public managers can analyze the decision-making opportunities in government by understanding the philosophical, political, and managerial-technical backgrounds, avoiding the harmful polarization of ideas present in the public environment today. This theoretical essay contributes to comprehending the nature of the knowledge structure applied to public administration. It also contributes to separate the private and the institutional dimensions. The reflection suggests that it is possible to avoid reifying political opinions and maintaining a democratic spirit, so managers can become more conducive to consider the plurality of ideas and be more open-minded without refraining from their convictions. These steps can be followed without losing focus on improving society's quality of life as an impartial and scientific outcome of public management.
\end{abstract}

Keywords: Public administration. Public management. Ethics. Philosophy. Political polarization.

\section{Cómo la filosofía puede iluminar la gestión pública en tiempos de polarización política}

\section{Resumen}

La polarización ha dominado el panorama político mundial durante la última década y ha afectado la gobernanza pública. El objetivo de este estudio es demostrar que a través de la comprensión de los antecedentes filosóficos, la política y las técnicas de gestión; el gestor de asuntos públicos podrá analizar, con mayor claridad, las oportunidades que implican la toma de decisiones en el ámbito gubernamental, evitando la dañina polarización de ideas, presente en el ámbito público actual. Mediante un ensayo teórico, se espera contribuir al conocimiento de las naturalezas que componen la estructura del conocimiento aplicado a la administración pública, así como a la separación entre lo institucional y lo privado, a la no cosificación de las opiniones políticas y al espíritu democrático; lo que permitiría que el gestor -sin abstenerse de sus convicciones- se volviera más propicio a considerar la pluralidad de ideas y tendiera a ser más tolerante con las opiniones contrarias, sin perder el foco en mejorar la calidad de vida de la sociedad como corolario de una gestión pública imparcial y científica.

Palabras clave: Administración pública. Gestión pública. Ética. Filosofía. Polarización política. 


\section{INTRODUÇÃO}

A polarização não apresenta um conceito consensual, pelo contrário, para Bramson et al. (2016) existem pelo menos nove tipos distintos de conceituá-la. Nem sempre negativa, ela é muitas vezes até desejável, como em ambientes democráticos de debate. Contudo o conceito que melhor se alinha ao contexto deste trabalho é o de que a polarização consiste na distribuição de ideias e opiniões em extremos opostos.

Episódios recentes como a eleição do polêmico presidente da República, Jair Bolsonaro, em 2018, o Brexit no Reino Unido, a eleição de Trump nos EUA, o movimento dos coletes amarelos na França e a invasão do Congresso dos EUA por partidários de Trump que tentavam impedir a sessão de certificação da vitória de Joe Biden trouxeram à pauta, no âmbito da gestão pública, a acentuada polarização de ideias como fator adverso, principalmente na abordagem de problemas do cotidiano que afetam a qualidade de vida dos cidadãos, e especialmente nas áreas da educação, saúde, segurança pública e economia.

Em ambientes políticos, como o Congresso Nacional, a polarização sempre existiu, uma vez que faz parte do sistema democrático. Todavia, após as eleições presidenciais de 2018, tornou-se nítido, por meio das redes sociais, que a proposição belicosa de ideias atingiu grande parte da massa populacional (Freitas \& Boaventura, 2018). Na administração pública, essa polarização nociva ficou evidente quando ocorreu a politização da pandemia do coronavírus em 2020. Enquanto os cientistas recomendavam o isolamento social (Dandekar \& Barbastathis, 2020), políticos ignoravam os fatos estimulando as pessoas a preservarem a economia em funcionamento ao custo de vidas ceifadas pelo vírus.

Muitas vezes o gestor público não se atenta ao fato de que as decisões para enfrentar os problemas sociais passam por uma cadeia de conhecimentos e valores que precisam ter a sua natureza estabelecida a fim de que a tomada de decisão seja mais científica e menos dogmática. Daí a necessidade de que todos os gestores da coisa pública conheçam pelo menos alguns dos principais pontos de debate do pensamento humano que ocorreram ao longo da história e que afetam diretamente a administração pública em seus aspectos ético, político e gerencial. Espera-se que esse arcabouço mínimo de conhecimento de humanidades permita ao gestor público praticar três atitudes inspiradas no filósofo Sandel (2015) e essenciais a um debate saudável de ideias: a separação entre o institucional e o privado, a não reificação das opiniões políticas e o espírito democrático. A escolha por Sandel e também por Rawls (2009), que será mencionado ao longo do texto, tem sua explicação. Buscou-se investigar na tradição filosófica autores que pudessem servir aos intentos deste trabalho. Tanto Sandel quanto Rawls trazem em suas obras preocupação pelo debate público de ideias e pela construção de visões filosóficas profundamente calcadas no objetivo de construção de uma sociedade justa. Muitos filósofos possuem o mesmo intento, mas contemporaneamente ambos se têm revelado proeminentes na abordagem de temas característicos da sociedade ocidental atual, buscando sempre a máxima razoabilidade para a solução de questões complexas como a construção de instituições justas. Prioriza-se Sandel nesta análise, sem desconsiderar o contraponto construtivo de Rawls, posto que os autores possuem posições distintas do ponto de vista teórico: Rawls é um escritor liberal, embora possa ser considerado "neutro" por determinados pontos de vista; enquanto Sandel é considerado um comunitarista. Contudo escolheu-se aqui não pontuar demasiadamente os aspectos liberais ou comunitaristas de suas visões, mas utilizar suas ideias como ferramentas filosóficas que sejam úteis ao gestor público em tempos de polarização.

Como pertencente às ciências sociais aplicadas, a administração pública precisa enfrentar as dúvidas éticas e políticas que antes eram quase exclusivas da filosofia, até mesmo como forma de amenizar os efeitos nocivos da polarização de ideias (Chaia \& Brugnago, 2014). A filosofia, por sua natureza, tem a característica de fornecer variadas respostas a problemas parecidos. Justamente por ter uma visão do todo, é capaz de auxiliar as ciências particulares de forma decisiva - algo que se pretende elucidar no presente artigo.

Por um lado, o gestor público é constantemente pressionado pelas demandas da sociedade e não pode esperar infindáveis debates políticos para se posicionar e tomar decisões que vão ao encontro dos anseios dos cidadãos. Por outro lado, decisões sem a devida reflexão podem levar a resultados desastrosos, especialmente em situações nas quais esse gestor lida com decisões que impactam a vida de milhares de pessoas, como no caso da pandemia da COVID-19. Esta necessária reflexão seria possível com o recurso ao pensamento filosófico, em específico por meio dos autores supracitados.

Ao discutir pontos importantes dos debates filosóficos, éticos e políticos que afetam as decisões relacionadas à gestão pública, tenciona-se estimular o gestor público e o estudante do campo de públicas à compreensão da natureza estrutural do conhecimento na administração pública, para que possa discernir entre a discussão saudável de pontos de vista e a polarização 
nociva de ideias, tão comum nos momentos atuais nos ambientes comunitários no Brasil. Espera-se ainda contribuir para que o gestor público sensibilize-se, sem se abster de suas conviç̧ões, em relação à pluralidade de opiniões, inerente aos ambientes públicos, e que tenda a ser mais tolerante aos juízos contrários, sem perder o foco na melhoria da qualidade de vida da sociedade como corolário da gestão pública.

A seguir serão abordados alguns conceitos fundamentais e aspectos da administração pública sob o contexto dos autores considerados relevantes para a presente discussão, do campo da ética e da política, a fim de se atingir o objetivo proposto.

\section{A ÉTICA NORMATIVA}

A ética considera as virtudes, os princípios e as consequências sobre os seres humanos, examinando a natureza dos valores morais e a justificação de sua aplicação à vida, sem descuidar da racionalidade, imparcialidade e liberdade moral (Skorupski, 2002). São diversas as perguntas que permeiam as reflexões éticas. O que são o bem e a vida virtuosa? Existem valores universais de bondade? Em um segundo nível em que essas questões são postas, por exemplo, existem respostas objetivas às questões anteriores? Essas questões superiores são denominadas metaéticas (Skorupski, 2002). As recentes discussões metaéticas resgataram o interesse pela objetividade da ética equiparando os "juízos morais" às proposições científicas (Williams, 2002). No século XX, por exemplo, o estudo da ética restringiu-se praticamente à discussão sobre os valores serem característicos do mundo ou meros produtos da preferência humana. Os problemas morais foram relegados, mas, depois de duas guerras, ascensão de ideologias totalitárias e várias tentativas de genocídio, aumentou-se a pressão por um pensamento moral sistemático sobre os valores fundamentais (Haldane, 2002). Em virtude disso, este tópico será dedicado ao estudo da necessidade da ética normativa na gestão pública.

Antes de definir de forma mais específica o escopo da ética a ser tratada no presente trabalho, faz-se necessário entender alguns conceitos. A diferenciação entre teorias éticas e definições éticas é fundamental. Enquanto as teorias éticas são extensas e complexas, as definições são mais simples e diretas (B. Gert \& J. Gert, 2017). Ninguém seria pretensioso o bastante para considerar que haveria alguma definição ética aplicável a qualquer discussão ética, contudo, há dois sentidos essenciais em que a ética tem sido abordada ao longo da história: o descritivo e o normativo. Enquanto no sentido descritivo a ética é entendida como o estudo de comportamentos particulares de um grupo - como a preferência política, a religião e as ideologias -; a ética normativa, por sua vez, refere-se a um código de conduta universal e aplicável a todos os seres racionais, sob certas condições específicas (B. Gert \& J. Gert, 2017).

Dois exemplos de atitudes morais que podem ilustrar a ética normativa são: evitar causar danos a terceiros e ser honesto. Embora relativistas éticos neguem a existência de qualquer moralidade universal, o que os torna conhecidos como "céticos morais", os denominados "realistas morais" acreditam que existe um mínimo de cooperação social para sustentar a existência de qualquer sociedade ao longo do tempo. Esse é o aspecto normativo da ética, ou seja, a definição substantiva de que é errado matar, roubar, trapacear, enganar e assim por diante (B. Gert \& J. Gert, 2017). Kant, defensor da ética deontológica, é quase um realista por sua visão do imperativo categórico (Williams, 2002). Para Kant (1995, p. 23), a moral é o racional, tanto que ele criou o axioma: "[...] procede apenas, segundo aquela máxima, em virtude da qual podes querer ao mesmo tempo que ela se torne em lei universal". Por isso, Kant buscou estabelecer o princípio supremo da moralidade, o qual denominou de imperativo categórico (Kant, 1995).

A ética normativa é tão poderosa que resiste ao teste das três principais tradições éticas que influenciaram o mundo ocidental: a ética aristotélica, baseada na virtude; a deontológica, baseada no dever; e a utilitarista, baseada nas consequências. O comprometimento com o interesse público e a busca do bem comum (Aristóteles, 1991), por exemplo, são ou pelo menos deveriam ser normativas para a gestão pública. A falta de honestidade de um gestor público que desvia dinheiro público para si tem ligação direta com este dualismo.

Do ponto de vista deontológico, Kant chamou de egoístas racionais os instrumentalistas, aqueles que rejeitam a moral argumentando que o indivíduo tem razão para: 1) buscar o que é bom para si mesmo e evitar o que lhe é prejudicial, 2) fazer tudo o que promova seus objetivos (Skorupski, 2002). Contudo pensadores como Mandeville (1732) defenderam que o egoísmo e os vícios humanos são bons para a sociedade. Ele alegava que a busca do autointeresse teria como consequência não intencional um caráter estabilizador para a sociedade. O "bem-comum" não seria um produto da bondade das pessoas, das suas virtudes, mas sim dos seus vícios individuais (Mandeville, 1732). 
O utilitarismo defende que o bem-estar do indivíduo possui valor ético intrínseco. Contudo o valor ético consiste no bem-estar geral e não individual, embora o bem-estar resida apenas nos indivíduos concretos. Logo, permanece a pergunta: e quando o aumento do bem-estar de X implica a diminuição do bem-estar de Y? Faz-se necessário o princípio da imparcialidade em que não se atribui peso maior a nenhum bem-estar individual na soma geral. Ainda que o utilitarismo tenha sido devastado por seus críticos, não há que se negar a preocupação que ele teve com o coletivo sobre o individual. Um exemplo é a explicação de Bentham (1996) para a punição. Levando em conta que utilidade, felicidade ou prazer são quase sinônimos na ótica utilitarista, e o devem ser levados ao máximo, a punição que causa dor ao transgressor é justificada porque produz uma maior redução de dor em outro lugar (Bentham, 1996).

Poucos absolutos éticos aplicam-se de forma normativa à gestão pública, tais como a honestidade e o comprometimento com o interesse público, pois, "[...] não há substituto para a preocupação direta com outras pessoas como fundamento da moral" (Nagel, 2001, p. 68). Nota-se que, para o cidadão e gestor público, a honestidade e o comprometimento com o interesse público podem ser convertidos em absolutos a serem seguidos; mas esses absolutos não devem ficar apenas na retórica. Embora a filosofia no mundo de língua inglesa tenha caído em um academicismo fechado, impenetrável ao cidadão comum, atrelada unicamente aos cânones objetivos da argumentação, Sócrates foi um exemplo de filósofo que se preocupava com a aplicação prática no dia a dia do conhecimento filosófico - sem perder o rigor, "[...] ele não agiu numa academia, mas no mercado e nas ruas de Atenas" (Wardy, 2002, p. 485). No exercício da gestão pública, a conformidade do discurso com a prática do dia a dia é fundamental, pois somente assim, aquele que discursa reveste-se de autoridade para propagar seu conhecimento.

O empirismo também tem confirmado a importância da ética normativa. Mesmo que por muitas vezes seus adeptos tenham combatido a ética por estar no campo do valor, não se pode negar que muitas proposições éticas têm sido confirmadas por meio do próprio empirismo. Um exemplo foi o estudo transsocietal empírico que revelou que a honestidade intrínseca das pessoas tem correlação inversa com o índice da "prevalência de violações das regras". Em outras palavras, honestidade tem alta correlação com hábitos de obediência às regras. Os resultados mostraram ainda que instituições fracas e legados culturais que geram violações de regras, tais como o jeitinho brasileiro, têm consequências econômicas adversas e prejudicam o bom funcionamento da sociedade (Gächter \& Schulz, 2016). O senso comum transmite a ideia de que a pobreza leva a sociedade a ser desonesta, todavia, este estudo, mostrou o inverso: o país perpetua a pobreza porque tem uma sociedade corrupta e desonesta.

Apesar do nome, a ética normativa assemelha-se mais a princípios e menos à norma propriamente dita. Nessa perspectiva abstrata de princípio em vez de regra, existem premissas ou princípios que todos de fato aceitam (Sayre-McCord, 2014). A defesa deste trabalho é que o gestor público deve gastar suas energias nesses pontos universais para não correr o risco de cair em debates circulares, pois tanto conservadores como progressistas, pelo menos retoricamente, são contra a corrupção e a favor do bem comum, que gera qualidade de vida.

\section{POLÍTICA}

Ao nível da aplicação prática, a política é a arena onde as ideias se digladiam de forma descritiva. A ética descritiva não é menos importante que a ética normativa. Entretanto, podemos classificá-la como de uma natureza distinta, haja vista que ela não pode ser aplicada de forma universal, visto que está no campo das opiniões pessoais, dos costumes, da cultura, nos quais se enquadram as opiniões políticas.

No campo político e filosófico, as disputas e debates sem uma conclusão plausível vêm de tempos longínquos. Na epistemologia, em que pese se ocupar de uma tarefa nobre, ou seja, a investigação sobre a natureza, as origens e a validade do conhecimento, a discussão sobre se conhecimento é crença verdadeira justificada, por exemplo, remonta ao Teeteto, o diálogo platônico (Platão, 2005), escrito antes de Cristo.

Não menos antiga e que afeta diretamente a gestão pública, a discussão epistemológica entre a autonomia humana e o realismo segue com defensores vorazes de ambos os lados. A ideia da autonomia humana nasce com os primeiros pensadores relativistas da história, aqueles que acreditam que nada no universo pode ser dado como certo, pois tudo é relativo. Esses filósofos que rejeitam as realidades externas à consciência humana alegam que as propriedades morais das pessoas não estão no mundo, mas são projetadas nele por sentimentos e reações (Williams, 2002). Enquanto a visão iluminista da ciência 
vincula a razão às verdades objetivas, os relativistas afirmam que a racionalidade é uma questão de adequação às regras de uma prática particular, tornando a verdade inatingível (Hollis, 2002).

Os pensadores, filósofos e cientistas que defendem a autonomia humana são normalmente relativistas uma vez que acreditam que as participações nas controvérsias atuais são condicionadas por compromissos, interesses pessoais e convicções dos indivíduos (Searle, 2002) - nesse caso, a objetividade é uma ilusão. Não existem fatos neutros nas interpretações quando alguém expõe algo, se está na verdade baseado em sua escolha pela teoria de preferência (Hollis, 2002). Para o relativismo, a sociedade será boa quando for boa por seus próprios padrões (Archard, 2002). A história é um exemplo de ciência particular em que a autonomia humana reina soberana. Segundo Pompa (2002), os juízos de valor dos historiadores afetam suas explicações de diversas formas e prejudicam a explicação do que realmente aconteceu, mas isso não mostra que o conhecimento histórico seja menos respeitável que as ciências naturais, que possuem pressupostos mais consensuais sobre a natureza da realidade.

Até mesmo na matemática, que se pressupõe ser uma ciência exata, o embate entre o realismo e o relativismo existe. Enquanto para o realista existe uma ordem fundamental eterna e imutável, os relativistas do conceptualismo aristotélico acreditam que o cosmo é um conjunto de coisas individuais que sofrem mudanças em um universo que é em parte contingente (Tiles, 2002). Dessa forma, a ideia de que o ser humano é autônomo e independe de qualquer tipo de realidade externa ganhou força, principalmente entre os progressistas.

Já a ideia de que o mundo à nossa volta está completamente subjugado à consciência humana tem muitos opositores. Os realistas acreditam que há um mundo externo às nossas consciências e uma realidade objetiva no mundo, e cabe aos cientistas o trabalho de desvendá-la. "Nossa aceitação do mundo externo é instintiva e poderosa: argumentações filosóficas não bastam para livrar-nos dela" (Nagel, 2001, p. 16). Moore acreditava com tanta segurança no realismo, que para provar a existência de um mundo externo bastava demonstrar a existência das próprias mãos (Baldwin, 2002).

Segundo Blackburn (2002), o realista procura a objetividade real considerando o mundo de fatos. O fundacionismo, por exemplo, utiliza a metáfora da construção de um edifício em que, se a cadeia de crenças regredisse infinitamente, chegar-se-ia aos tipos de crenças que não precisam de justificação por serem autoevidentes. Um exemplo disso seria: "um mais um é igual a dois" (Grayling, 2002). Para Moore (2002), sempre haverá um tipo epistêmico que pode superar todos os demais; por isso, a ideia de que há um tipo último, absoluto parece correta. Esta é a razão pela qual os cientistas, filósofos e pensadores conservadores tendem a se aproximar da epistemologia realista e do empirismo, pois as verdades abstraídas do mundo das realidades naturais são muito dependentes dos experimentos. Já os progressistas tendem a depender mais do racionalismo, uma vez que para eles a consciência humana sobrepõe o mundo natural.

Para os racionalistas, as verdades necessárias são alcançadas pela intuição e inferência racional, confirmadas por meio de instrumentos como a lógica e a matemática (Grayling, 2002). Para os empiristas, o conhecimento autêntico no mundo atinge-se por meio da experiência e utilização de instrumentos tais como telescópios e microscópios. Os empiristas acreditam que a ciência natural, por meio de observações e experiências, leva ao conhecimento (Grayling, 2002). Francis Bacon, Thomas Hobbes, John Locke e David Hume fortaleceram a epistemologia empírica. As obras do Círculo de Viena, entre os anos 1920 e 1930, demonstraram que o empirismo foi o corolário do positivismo lógico (Taliaferro, 2002). Hume acreditava de tal forma no empirismo, que chegou a afirmar que todas as suas teses baseiam-se na experiência - para ele somente a experiência estabelece os fatos. As experiências que não são testáveis ou revisáveis são inimigas da genuína investigação científica (Hume, 2009).

No campo de públicas, a tensão entre administração e ciência política é uma realidade constante (Paula, 2005). Como o gestor público pode se desvencilhar destes paradoxos que muitas vezes paralisam o pensamento e a argumentação em sua atuação? Neste tipo de pergunta reside uma armadilha para gestores públicos. A estes não cabe resolver dilemas que atravessam milênios de discussão na comunidade política e filosófica. Não porque a administração pública seja uma ciência inferior, mas porque os aspectos políticos da filosofia, especialmente das áreas afetas à gestão pública no que tange à epistemologia e à ética, nunca alcançaram consenso, pelo menos até hoje. Esse fato torna a política uma ciência menor? De forma alguma. A falta de consenso decorre da natureza descritiva da política.

A ética também tem seus aspectos políticos que não demandam consenso justamente por se tratar de opiniões que divergem. Dessa forma, o gestor público deve adotar uma postura científica aberta à investigação, ao diálogo, nunca se posicionando de forma dogmática, como portador de verdades incontestáveis. Por exemplo, a discussão ética que atravessa milênios de debate sem solução, a do hedonismo versus estoicismo, há de um lado o estoicismo, que preconiza o cultivo de uma disciplina moral, tendo a razão como fim último da vida. De outro lado, os adeptos do hedonismo buscam o prazer como corolário da 
existência. Em outras palavras, enquanto para os hedonistas o prazer e a ausência de dor eram o fim último da vida; para os estoicos, o fim último era viver segundo a razão (Wardy, 2002). Poucas pessoas negam que poder, dinheiro e prazer sejam coisas boas em si mesmas. Até mesmo religiosos como Paulo, o apóstolo cristão, atribuiu a raiz de todos os males ao "amor" ao dinheiro, mas não ao dinheiro em si mesmo (Sociedade Bíblica do Brasil [SBB], 1995). Contudo esses três elementos formam o tripé do hedonismo, que foi defendido e combatido por muitos filósofos ao longo da história. Para o gestor público, é evidente que esses três elementos têm o poder de potencializar a bestialização humana, basta notar que quase todo crime tem sua origem na obstinação por dinheiro, poder ou prazer. Por essa razão, os conservadores alinham-se aos estoicos para regular os desejos hedonistas na arena pública; enquanto os progressistas, de forma contrária, buscam delegar ao indivíduo a liberdade de escolher seus próprios caminhos, ainda que essas decisões possam ser prejudiciais a ele mesmo. Isso explica boa parte das tensões que ocorrem na arena pública em matérias como a descriminalização de drogas, do aborto e da eutanásia.

Ao gestor público cabe o bom senso em equilibrar a promoção do bem-estar geral por meio da regulação de interesses contraditórios, sem abrir mão da garantia à liberdade que conduz à felicidade de cada indivíduo. Nesse paradoxo, a polarização concernente às decisões em políticas públicas pode comprometer o espírito da imparcialidade tão necessário aos gestores públicos. Diante disso, a melhor opção reside na moldura institucional aliada à praxe democrática. 0 melhor gestor é aquele que envolve o coletivo e a decisão de todos sob bases institucionais democráticas, pois bons gestores públicos são embebidos de sentimentos republicanos. Isso afeta diretamente a tomada de decisões e fica evidente na análise das teorias da administração pública feita por Denhardt (2013), em que ele defende que tais teorias deveriam basear-se em valores como equidade, justiça e liberdade e, não, focar em questões relacionadas com poder, como as teorias organizacionais preconizam.

Esses conflitos atravessam milênios, e por isso são considerados insolúveis por muitos (Skorupski, 2002), razão pela qual os gestores públicos que lidam cotidianamente com demandas sociais reais e iminentes devem refletir se vale a pena despender energia em debates circulares sem consenso, derivados das opiniões políticas divergentes, enquanto a luta pelo que é normativo fica em segundo plano.

A seguir se explicitará como a política, não importando o seu viés, carece de técnicas gerenciais para se converter em políticas públicas palpáveis ao cidadão.

\section{TÉCNICAS GERENCIAIS}

As técnicas gerenciais, muito utilizadas no âmbito da administração pública ou privada, são de natureza situacional e transitória. Remontam a 3.000 anos a.C., quando os sumérios fizeram seus primeiros registros de transações de negócios. Platão, em sua obra República, também demonstrou a importância de técnicas gerenciais como a especialização de tarefas e competências. A administração, contudo, pode ser considerada uma ciência recém-nascida, visto que a escola de administração clássica surge a partir de 1885 em decorrência da Revolução Industrial (Pindur, Rogers Sandra \& Suk Kim, 1995).

A chamada administração científica de Frederick Taylor foi muito bem utilizada no período da Revolução Industrial para promover o aumento da produtividade e da eficiência. Contudo o aumento da eficiência e dos lucros não impediu o abuso do poder econômico por parte dos empregadores, requerendo dessa jovem ciência uma guinada ética, marcada pelo surgimento da escola das relações humanas com Elton Mayo no mundo das teorias organizacionais. Mayo e seus contemporâneos perceberam que não bastavam incentivos econômicos para melhorar a produtividade, na medida em que a salubridade do ambiente e a boa relação interpessoal com os superiores afetavam a motivação humana no agir (Pindur et al., 1995). Era necessário que o ser humano não mais fosse visto como uma mera máquina de fazer dinheiro, mas passasse a ser entendido também como um ser social e com uma dignidade intrínseca.

O caráter transitório das técnicas gerenciais também não pode ser esquecido. As técnicas, ideias e conhecimentos no mundo da gestão, embora presentes na história desde tempos remotos, têm sido adornados de modismos. Os autores que revestem técnicas antigas com uma nova roupagem são elevados ao status de "gurus" (Parker Lee \& Ritson, 2005). Ao contrário da ética normativa, que, além de ser perene, permeia as demais naturezas do conhecimento; as técnicas gerenciais só devem ser aplicadas com a devida análise do contexto e serem guiadas pelos princípios normativos que governam o espírito republicano, sob pena de não surtirem os efeitos desejados (Rohan, 1986). 
A dependência das técnicas gerenciais da ética normativa exprime-se por meio da história da ética aplicada. No caso específico deste estudo, a história da administração pública mostra que as motivações no ato de servir ao público são diferentes daquelas incentivadas na iniciativa privada (Perry, Brudney, Coursey \& Littlepage, 2008). A motivação humana, quando se tem o espírito público do bem comum como alvo, passa por princípios como a compaixão, o comprometimento pelo interesse público e o autossacrifício (Perry \& Hondeghem, 2008).

Os códigos de ética determinam os valores profissionais e suas responsabilidades e são caracterizados pelo diálogo multidisciplinar. As práticas normativas vão se manifestando desde o ensino universitário até os pareceres nas empresas. Nesse contexto, contudo, o foco está nas situações concretas, pois, o perigo niilista do desenvolvimento técnico-científico é amenizado à medida que valor e finalidade se ligam a uma filosofia de natureza teleológica (Parizeau, 2003). Com essa consciência, o administrador público desenvolve a compreensão de que, sem a ética normativa, a tecnologia e o conhecimento técnico-científico podem trazer muitos males à sociedade, como ocorreu por ocasião da Segunda Guerra Mundial.

As técnicas gerenciais no setor público são expressas na forma de políticas públicas. Desse modo, essas práticas gerenciais também sofrem forte influência do contexto político. O processo de tomada de decisões no campo das políticas públicas tem sido explicado principalmente com base em três modelos: múltiplos fluxos, coalizões de advocacia e equilíbrio pontuado. Esses três modelos admitem a influência de relações de poder de diversos atores (Almeida \& Gomes, 2018).

As técnicas gerenciais perpassam todo o ciclo de políticas públicas, incluindo as fases de identificação do problema, formação da agenda, formulação de alternativas, tomada de decisão, implementação, avaliação e extinção (Secchi, 2013). Contudo cada técnica tem sua aplicação muito bem definida conforme a necessidade correspondente às respectivas fases. A técnica da árvore de decisão, por exemplo, é compatível com a formação de agenda, pois, a lista de prioridades de atuação de um governo tornar-se-á a agenda de políticas públicas (Secchi, 2013). Dessa forma, as técnicas funcionam como ferramentas à disposição do artesão que as utiliza conforme a necessidade que o momento requer.

\section{A CLASSIFICAÇÃO DAS TRÊS NATUREZAS DO CONHECIMENTO EM ADMINISTRAÇÃO PÚBLICA}

Como exposto até aqui, existem três naturezas distintas do conhecimento que permeiam a gestão pública. A ético-normativa, a político-descritiva e a técnico-gerencial. Embora não se possa afirmar que uma é mais importante que a outra, elas têm papéis completamente diversos e capilaridades distintas também.

\section{Figura 1}

\section{Naturezas do Conhecimento em Administração Pública}

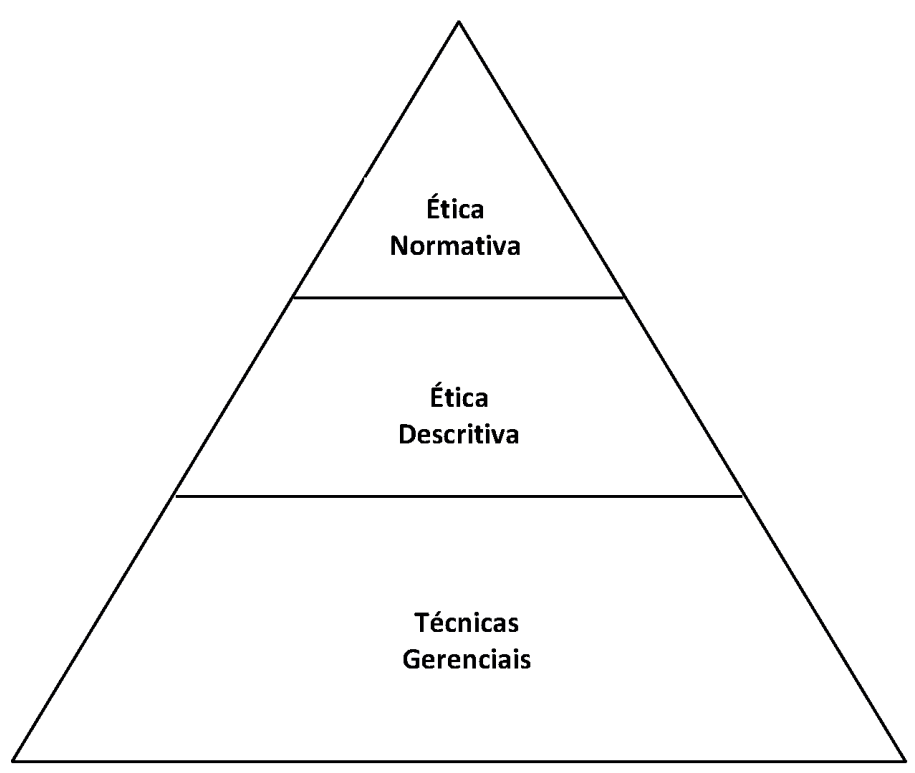

Fonte: Elaborada pelos autores. 
As questões da ética normativa são de natureza universal na administração pública. Por essa razão, permeiam todas as demais naturezas do conhecimento tornando-as dependentes da aplicação normativa da ética. Em outras palavras, se a ética normativa não for bem aplicada, a política e as técnicas gerenciais não proporcionarão a qualidade de vida tão almejada pela administração pública. Por isso, não são poucos os pensadores que acreditam que o cuidado com a ética no seu sentido normativo é uma das principais razões que diferenciam países desenvolvidos dos subdesenvolvidos (Gächter \& Schulz, 2016; Gundlach \& Paldam, 2009; Treisman, 2000).

A ciência particular da gestão pública faz-se, essencialmente, por meio de políticas públicas baseadas em dados reais e experimentos empíricos (Secchi, 2013), mas estes não podem prescindir do fato de que o gestor público deve se orientar por valores universais de cidadania, honestidade e comprometimento com o interesse público como princípios racionais precursores dos experimentos.

É importante notar que a ética normativa não concorre ou é inimiga da ética descritiva. Ela coopera para que a ética descritiva funcione bem, independentemente da posição política aderente. A filosofia analítica já abordou esse problema por meio da análise do paradoxo analítico versus sintético. As verdades analíticas são proposições como " $2+2=4$ ", "triângulos são figuras de três lados", ou seja, a verdade da proposição é a priori, necessária, determinada por seu próprio significado. Já as proposições sintéticas são derivadas de um fato empírico, a posteriori, contingente, por exemplo: "jovens solteiros morrem mais cedo". Os positivistas afirmavam que as questões relevantes ou eram analíticas ou sintéticas, as demais proposições eram sem sentido ou não verificáveis (Searle, 2002). No entanto, no afã de demolir a ética, os positivistas entraram na seara dos valores distinguindo as elocuções valorativas, tais como "é errado roubar", como não verificáveis, portanto, desprovidas de significado (Searle, 2002). Hutcheson afirma que os seres humanos têm um senso moral que comunica, por meio da experiência, as ideias morais que movem suas ações. Ele explica porque determinadas opiniões morais são comuns às pessoas de todas as épocas e culturas e também porque essas opiniões são despertadas espontaneamente, independentemente de nossa vontade, quando uma ação ofensiva causa indignação (Hutcheson \& Leechman, 1755).

Hume (2009), no entanto, acreditava que os juízos morais ou normativos não são proposições genuínas, mas apenas expressões afetivas de decisões ou volições. Muitos positivistas levaram esse pensamento humiano a ter grande influência nas culturas contemporâneas, embora na filosofia esteja perdendo terreno (Skorupski, 2002). Ambos os pontos de vista estão corretos se pensarmos nas categorias das naturezas. A natureza descritiva da política não a coloca em oposição à natureza universal da ética normativa. Portanto não se trata de qual ética é superior, mas de que a ética descritiva é altamente dependente da ética normativa como pré-requisito prático que a antecede.

A intuição do cientista, ao iniciar uma pesquisa, sempre conterá elementos políticos de sua visão de mundo; contudo, os pesquisadores sérios não distorcem a metodologia para chegar aos fins desejados. Mesmo que isso ocorra, existe a comunidade científica como crítica do trabalho dos estudiosos. Portanto o gestor público deve se ater a uma investigação sincera da avaliação dos resultados das políticas públicas, independente do viés epistemológico ou político de sua preferência, nunca se esquecendo de que, a despeito do seu ponto de vista político, uma ética normativa saudável deve permeá-lo.

Quanto às questões operacionais e técnicas de gestão, além de serem também altamente dependentes da ética normativa, estão em constante estado de obsolescência. Por isso, são de natureza situacional e transitória. Em que pese a condição permanente de inovação das técnicas gerenciais, elas guardam relação com o fio condutor das teorias de administração pública, que se baseiam na herança intelectual de Max Weber, com ênfase na burocracia racional e influência política de Wilson, que destaca a dicotomia entre política e administração (Denhardt, 2013). Por essa razão, as técnicas gerenciais são indispensáveis ao processo de tomada de decisão na administração pública.

Para que as técnicas gerenciais não se tornem ferramentas em mãos erradas, é preciso diminuir o descompasso entre as dimensões econômico-financeira, institucional-administrativa e sociopolítica. A eficiência técnica não pode ser almejada como no modelo da Nova Gestão Pública (NGP), em que o movimento gerencialista a buscou em detrimento da democracia e do interesse público (Paula, 2005).

A classificação das três naturezas do conhecimento em administração pública é condição necessária, mas não suficiente para que o gestor público possa analisar a tomada de decisão nos ambientes governamentais, evitando a polarização nociva de ideias. Desse modo, faz-se necessário invocar, finalmente, as três atitudes inspiradas em Sandel, a fim de se atingir este 
objetivo, a saber: a separação entre o institucional e o privado, a não reificação das opiniões políticas e o espírito democrático (Sandel, 2015). Aqui, pode-se ver com clareza como a dimensão da ética normativa importa para a tomada de decisão do gestor público.

A divisão entre a esfera institucional, que se constitui de coletividade, e a esfera privada, que se constitui do particular, é fundamental para que haja um debate público de ideias de qualidade. Isso se faz necessário porque em algum momento da história humana ocorreu a diferenciação entre o que pertence ao grupo ou à coletividade e o que pertence ao indivíduo. As crenças pessoais, gostos, propriedades particulares pertencem ao indivíduo, que exerce a sua liberdade limitada pela res publica, ou coisa pública. Equivale a dizer que, em maior ou menor grau, a individualidade está debaixo da supremacia da coletividade (Bobbio, 2007). Assim, as instituições promovem restrições que estruturam as relações políticas, econômicas e sociais (North, 1991).

Ao considerar a existência das esferas individual e institucional, Rawls (2005) reconheceu que os seres humanos não devem se afastar de suas crenças, devoções e lealdades; no entanto, essas conviç̧ões pessoais não deveriam ser impostas às outras pessoas no nível institucional. A não reificação das próprias crenças, ideias e opiniões políticas faz parte do pluralismo sensato do mundo moderno. Rawls (2009) recomendava a utilização do véu da ignorância, uma experiência mental em que o indivíduo simula não saber a que classe pertence ao definir os princípios sociais.

Por último, mesmo que as opiniões políticas divergentes sejam inerentes às sociedades democráticas, o espírito democrático, para além de um sistema de democracia institucional, permite que pessoas superem as guerras culturais. A explicação reside na consciência de que a reflexão ética não é uma busca individual, mas sim coletiva. A consciência de que, apesar da tentativa, a busca de princípios de justiça neutros é um equívoco, não permite que princípios éticos sociais sejam deliberados pelo indivíduo em dissonância com a comunidade (Sandel, 2015). Neste ponto, o pensamento de Sandel diverge do pensamento de Rawls, por considerar a inserção comunitária como decisiva para a deliberação sobre valores que devam nortear decisões coletivas. Importante salientar, aqui, que este artigo, conforme mencionado na introdução, não teve como objetivo aprofundar estas diferenças. Conclui-se esta breve análise com a constatação de que um maior aprofundamento de tais temas e autores é preciso, visando demonstrar como a ética normativa e, de forma mais geral, a filosofia podem iluminar a tomada de decisão na gestão pública em tempos de polarização política. Afinal, tais tempos pedem cada vez mais o exercício reflexivo e o acesso à tradição filosófica e à argumentação para evitar decisões equivocadas e prevenir futuras polarizações e outros problemas à gestão pública.

\section{CONSIDERAÇÕES FINAIS}

Com recurso a Sandel (2015) e Rawls (2005), pode-se concluir que, por meio da separação entre o institucional e o privado, da não reificação das opiniões políticas e do espírito democrático, é possível promover um debate público de qualidade. Quando o gestor público toma consciência do pano de fundo filosófico e da estrutura do conhecimento que orientam o processo de tomada de decisão na administração pública, como foi exposto neste estudo, espera-se que ele, como salientaram Sandel (2015) e Raws (2005), não se descuide da racionalidade, da imparcialidade e da liberdade moral. Embora exista uma nítida polaridade de ideias no mundo das questões políticas aplicadas à gestão pública; aos estudiosos dessa ciência é desejável o equilíbrio sensato entre estes polos. Isso não significa dizer que não é adequado ao gestor público posicionar-se, pois a teoria ética não consiste simplesmente em respostas ponderadas às razões para o agir (Skorupski, 2002). 0 gestor da coisa pública, contudo, não pode se furtar ao dever de tomar decisões técnicas, baseadas em fatos, velando pelo correto uso das metodologias científicas, independentemente de suas crenças e opções políticas. Quem tem o poder de verificar esses fatos? A comunidade científica em conjunto com os praticantes da gestão pública, ambos aliados ao controle social.

Como exposto, muitos conflitos de ideias atravessaram milênios e não encontraram consenso. Seria temerário que, para implementar as políticas públicas, os gestores, antes, tentassem resolver esses dilemas. Mas, ao conhecer a natureza desses embates, eles se tornarão mais propícios a considerar o efeito circular dessas discussões e, dessa forma, prevenirem-se em relação à polarização das questões que paralisam as decisões no âmbito da administração pública. Ademais, entender que o progresso de uma sociedade depende da vigilância permanente dos princípios universais que a sustentam é essencial para que a política e as técnicas gerenciais alcancem os resultados esperados no âmbito dessa ciência social aplicada denominada gestão pública. 
Dentre as limitações deste artigo, podem-se destacar duas importantes perguntas que ficaram sem resposta. A primeira é a seguinte: seria possível provar empiricamente que a ética normativa, que define os princípios universais da administração pública, é tão importante para alcançar o aumento da qualidade de vida da sociedade a que a administração pública se propõe? Por consequência, sendo possível provar a importância empírica da ética normativa para a gestão pública, quais seriam os princípios universais essenciais da gestão pública? Se, por um lado, este artigo não conseguiu responder a estas duas perguntas; por outro lado, estes questionamentos são excelentes caminhos para direcionar pesquisas futuras. E, nesse caso, o caminho inverso também é possível, ou seja, como a administração pública e seus casos concretos podem ajudar a iluminar a filosofia.

Acrescenta-se ao objetivo principal deste estudo o fato de que o conhecimento é o único caminho para a autonomia intelectual e o desenvolvimento da formação de opinião. Isso não se aplica apenas aos servidores públicos, mas aos estudantes e a quaisquer outros cidadãos que prezem pela independência do senso crítico. O gestor público, para muito além dos domínios das técnicas de gestão, precisa dominar um portfólio cognitivo de humanidades e sensibilidades para entender que muitas vezes a melhor solução técnica pode prejudicar enormemente as pessoas. Esta deveria ser uma das maiores preocupações dos governos. O pluralismo de valores é uma característica inevitável da existência moderna, não obstante os conflitos requeiram princípios consensuais para regular os custos e benefícios distribuídos entre os membros da sociedade. Na medida em que os cidadãos forem mais tolerantes, civilizados e dispostos a fazer sacrifícios em nome do bem comum, a sociedade se tornará mais justa (Rawls, 2009). Neste diapasão, não há repreensão para aqueles que promovem a paz, a tolerância, a cordialidade e o bem viver comunitário.

\section{AGRADECIMENTOS}

Os autores agradecem ao Programa de Apoio à Pós-Graduação (PROAP/CAPES) pelos recursos utilizados no custeio do serviço de versão do presente artigo para a língua inglesa. 


\section{REFERÊNCIAS}

Almeida, L. A., \& Gomes, R. C. (2018). Processo das políticas públicas: revisão de literatura, reflexões teóricas e apontamentos para futuras pesquisas. Cadernos EBAPE.BR, 16(3), 444-455.

Archard, D. (2002). Filosofia política e social. In N. Bunnin, \& E. P. Tsui-James (Eds.), Compêndio de Filosofia (pp. 257-289). São Paulo, SP: Edições Loyola.

Aristóteles. (1991). Ética a Nicômaco (Vol. 2). São Paulo, SP: Nova Cultural.

Baldwin, T. (2002). Moore. In N. Bunnin, \& E. P. Tsui-James (Eds.), Compêndio de Filosofia (pp. 675-680). São Paulo, SP: Edições Loyola.

Bentham, J. (1996). The collected works of Jeremy Bentham: An introduction to the principles of morals and legislation. Oxford, UK: Clarendon Press.

Blackburn, S. (2002). Metafísica. In N. Bunnin, \& E. P. Tsui-James (Eds.), Compêndio de Filosofia (pp. 65-90). São Paulo, SP: Edições Loyola.

Bobbio, N. (2007). Estado, governo, sociedade, por uma teoria geral da política. São Paulo, SP: Paz e Terra.

Bramson, A., Grim, P., Singer, D. J., Fisher, S., Berger, W., Sack, G., ... Flocken, C. (2016). Disambiguation of social polarization concepts and measures. Journal of Mathematical Sociology, 40(2), 80-111. Recuperado de https://doi.org/10.1080/0022250X.2016.1147443

Chaia, V. L. M., \& Brugnago, F. (2014). A nova polarização política nas eleições de 2014: radicalização ideológica da direita no mundo contemporâneo do Facebook. Aurora. Revista de Arte, Mídia e Política, 7(21), 99-129.

Dandekar, R., \& Barbastathis, G. (2020). Quantifying the effect of quarantine control in Covid-19 infectious spread using machine learning. medRxiv. Recuperado de https://doi.org/10.1101/2020.04.03.20052084

Denhardt, R. B. (2013). Teorias da Administração Pública (6a ed.). São Paulo, SP: Cengage Learning.

Freitas, E. C., \& Boaventura, L. H. (2018). Cenografia e ethos: o discurso da intolerância e polarização política no Twitter. Letras de Hoje, 53(3), 449-458.

Gächter, S., \& Schulz, J. F. (2016). Intrinsic honesty and the prevalence of rule violations across societies. Nature, 531(7595), 496-499. Recuperado de https://doi.org/10.1038/nature17160

Gert, B., \& Gert, J. (2017). The Definition of Moralit. In E. N. Zalta (Ed.), Stanford Encyclopedia of Philosophy Archive. Recuperado de https:// plato.stanford.edu/archives/fall2017/entries/morality-definition/

Grayling, A. C. (2002). Epistemologia. In N. Bunnin, \& E. P. Tsui-James (Eds.), Compêndio de Filosofia (pp. 39-63). São Paulo, SP: Edições Loyola.

Gundlach, E., \& Paldam, M. (2009). The transition of corruption: From poverty to honesty. Economics Letters, 103(3), 146-148. Recuperado de https://doi.org/10.1016/j.econlet.2009.03.002

Haldane, J. (2002). Ética aplicada. In N. Bunnin, \& E. P. Tsui-James (Eds.), Compêndio de Filosofia (pp. 717-726). São Paulo, SP: Edições Loyola.
Hollis, M. (2002). Filosofia das ciências sociais. In N. Bunnin, \& E. P. Tsui-James (Eds.), Compêndio de Filosofia (pp. 357-387). São Paulo, SP: Edições Loyola.

Hume, D. (2009). Tratado da natureza humana (2a ed.). São Paulo, SP: Unesp.

Hutcheson, F., \& Leechman, W. (1755). A system of moral philosophy (Vol. 1). Cambridge, UK: Cambridge University Press.

Kant, I. (1995). Fundamentação da metafísica dos costumes. São Paulo, SP: Companhia Editora Nacional.

Mandeville, B. (1732). The Fable of the Bees or Private Vices, Publick Benefits (I. LIBERTY FUND Ed. Vol. 1). Indianapolis, Indiana: The Online Library of Liberty.

Moore, A. W. (2002). Filosofia da lógica. In N. Bunnin, \& E. P. Tsui-James (Eds.), Compêndio de Filosofia (pp. 139-164). São Paulo, SP: Edições Loyola.

Nagel, T. (2001). Uma breve introdução à filosofia. São Paulo, SP: Martins Fontes.

North, D. C. (1991). Institutions. Journal of Economic Perspectives, 5(1), 97-112.

Parizeau, M.-H. (2003). As relações entre a filosofia moral e a ética aplicada. In C. A. Gianotti (Ed.), Dicionário de Ética e Filosofia Moral (Vol. 1, pp. 595-600). São Leopoldo, RS: Editora Unisinos.

Parker Lee, D., \& Ritson, P. (2005). Fads, stereotypes and management gurus: Fayol and Follett today. Management Decision, 43(10), 13351357. Recuperado de https://doi.org/10.1108/00251740510634903

Paula, A. P. P. (2005). Por uma nova gestão pública: limites e potencialidades da experiência contemporânea. Rio de Janeiro, RJ: FGV.

Perry, J. L., Brudney, J. L., Coursey, D., \& Littlepage, L. (2008). What Drives Morally Committed Citizens? A Study of the Antecedents of Public Service Motivation. Public Administration Review, 68(3), 445458. Recuperado de https://doi.org/10.1111/j.1540-6210.2008.00881.x

Perry, J. L., \& Hondeghem, A. (2008). Motivation in public management: the call of public service. New York, NY: Oxford University Press.

Pindur, W., Rogers Sandra, E., \& Suk Kim, P. (1995). The history of management: a global perspective. Journal of Management History, 1(1), 59-77. Recuperado de https://doi.org/10.1108/13552529510082831

Platão. (2005). Teeteto. Lisboa, Portugal: Gulbenkian.

Pompa, L. (2002). Filosofia da história. In N. Bunnin, \& E. P. Tsui-James (Eds.), Compêndio de Filosofia (pp. 417-444). São Paulo, SP: Edições Loyola.

Rawls, J. (2005). Political liberalism. New York, NY: Columbia University Press.

Rawls, J. (2009). A theory of justice. Cambridge, MA: Harvard university press.

Rohan, T. M. (1986). Management by magic? Some fad techniques promise more than they can deliver. Industry Week, 230, 56. 
Sandel, M. J. (2015). Justiça O que é fazer a coisa certa. Rio de Janeiro, RJ: Civilização Brasileira.

Sayre-McCord, G. (2014). Metaethics. Stanford Encyclopedia of Philosophy. Recuperado de https://plato.stanford.edu/archives/ sum2014/entries/metaethics/

Searle, J. R. (2002). Filosofia contemporânea nos Estados Unidos. In N. Bunnin, \& E. P. Tsui-James (Eds.), Compêndio de Filosofia (pp. 1-23). São Paulo, SP: Edições Loyola.

Secchi, L. (2013). Políticas públicas: conceitos, esquemas de análise e casos práticos (2a ed.). São Paulo, SP: Cengage Learning.

Skorupski, J. (2002). Ética. In N. Bunnin, \& E. P. Tsui-James (Eds.), Compêndio de Filosofia (pp. 197-227). São Paulo, SP: Edições Loyola.

Sociedade Bíblica do Brasil. (1995). Bíblia Sagrada - Antigo e Novo Testamentos (2a ed.). São Paulo, SP: Autor.
Taliaferro, C. (2002). Filosofia da religião. In N. Bunnin, \& E. P. Tsui-James (Eds.), Compêndio de Filosofia (pp. 445-482). São Paulo, SP: Edições Loyola.

Tiles, M. (2002). Filosofia da matemática. In N. Bunnin, \& E. P. Tsui-James (Eds.), Compêndio de Filosofia (pp. 325-356). São Paulo, SP: Edições Loyola.

Treisman, D. (2000). The causes of corruption: a cross-national study. Journal of Public Economics, 76(3), 399-457. Recuperado de https:// doi.org/10.1016/S0047-2727(99)00092-4

Wardy, R. (2002). Filosofia grega antiga. In N. Bunnin, \& E. P. Tsui-James (Eds.), Compêndio de Filosofia (pp. 483-499). São Paulo, SP: Edições Loyola.

Williams, B. (2002). Filosofia contemporânea: um segundo olhar. In N. Bunnin, \& E. P. Tsui-James (Eds.), Compêndio de Filosofia (pp. 25-37). São Paulo, SP: Edições Loyola.

Ellysson Fernandes Rosa

ORCID: https://orcid.org/0000-0002-9401-7828

Mestre em Administração pela Universidade Federal de Goiás (UFG); Professor na Faculdade Unida de Campinas (FacUnicamps).

E-mail: ellysson.rosa@facunicamps.edu.br

Estela Najberg

ORCID: https://orcid.org/0000-0002-2852-4442

Doutora em Administração pela Fundação Getulio Vargas (FGV EAESP); Professora Associada na Universidade Federal de Goiás (FACE-UFG)

E-mail: estela@ufg.br

Lauren de Lacerda Nunes

ORCID: https://orcid.org/0000-0002-7429-393X

Doutora em filosofia pela Universidade Federal de Santa Maria (UFSM); Professora Adjunta da Universidade Federal do Pampa (UNIPAMPA).

E-mail: laurennunes@unipampa.edu.br

João Luiz Passador

ORCID: https://orcid.org/0000-0002-0460-8852

Doutor em Administração pela Fundação Getulio Vargas (FGV EAESP); Professor Titular pela Universidade pública em São Paulo (FEARP/USP).

E-mail: jlpassador@usp.br 